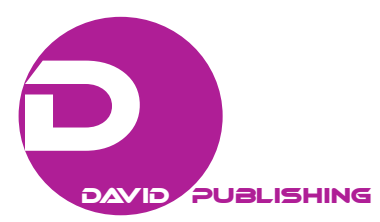

\title{
A Selection Process as a Game
}

\author{
Manuel Alberto M. Ferreira \\ Instituto Universitário de Lisboa (ISCTE-IUL), Lisbon, Portugal \\ Maria Cristina Peixoto de Matos \\ Instituto Politécnico de Viseu (IPV)-Escola Superior deTecnologia e Gestão de Viseu (ESTGV), Viseu, Portugal
}

\begin{abstract}
The aim of this paper is to exemplify how to solve the problem of selecting a candidate up to his/her acceptance trough game theory. The originality this paper proposes is how this problem will be approached: It will be treated as a single game which is made up of two parts, going as far as to state that the payoffs in the first part of the game will be the mediators of the second part of the game.
\end{abstract}

Keywords: selection process, game theory, two-part game, code form

\section{Introduction}

A presidential decree reduced the number of candidates to the vice-presidency to three people. Each of the three candidates are ranked on a scale from 1 (lowest) to 10 (highest). The presidential board attributed 10 points, 8 points, and 5 points to the candidate classified in 1 st place, 2 nd place, and 3 rd place, respectively. The probabilities candidate $\mathrm{i}(\mathrm{i}=1,2,3)$ accepting the $\mathrm{j}$-th offer to run for the vice-presidency have been defined, considering that the first $\mathrm{j}-1$ offers to the others have been declined, and are denoted by $p_{i j}$ and the respective values are in Table 1 .

Table 1

Acceptance Probabilities

\begin{tabular}{llll}
\hline Player 1 & $p_{11}=0.5$ & $p_{12}=0.2$ & $p_{13}=0.0$ \\
Player 2 & $p_{21}=0.9$ & $p_{22}=0.5$ & $p_{23}=0.2$ \\
Player 3 & $p_{31}=1.0$ & $p_{32}=0.8$ & $p_{33}=0.4$ \\
\hline
\end{tabular}

The question is: What is the order in which the three potential candidates can be offered the vice-presidential nomination if the presidential decree imposes the expected number of points maximization, supposing that no candidate is requested more than once and, each time a candidate rejects, another one is requested, until at least one has accepted or all have rejected?

\section{Game Details}

Acknowledgements: This work is financed by national funds through FCT—Fundação para a Ciência e Tecnologia, I. P., under the projects UID/MULTI/4466/2016 and UID/Multi/04016/2016. Furthermore, the authors thank the Instituto Universitário de Lisboa and ISTAR-IUL, and Instituto Politécnico de Viseu and CI\&DETS for their support.

Manuel Alberto M. Ferreira, full professor, Instituto Universitário de Lisboa (ISCTE-IUL), Lisbon, Portugal.

Maria Cristina Peixoto de Matos, adjunct professor, Instituto Politécnico de Viseu (IPV)-Escola Superior deTecnologia e Gestão de Viseu (ESTGV), Viseu, Portugal.

Correspondence concerning this article should be addressed to Manuel Alberto M. Ferreira, ISCTE-IUL, Av. das Forças Armadas, Lisboa 1649-026, Portugal. 
This game which is made up of two parts - a selection process and an acceptance process - attests that the payoffs in the first part of the game (potential candidates) will be the intermediaries of the second (decision elements). Thus:

\section{Players}

Candidate classified in 1st place-1;

Candidate classified in 2nd place-2;

Candidate classified in 3rd place- 3 ;

Presidential Board- 4 .

\section{Strategies ${ }^{1}$}

Potential candidates. The strategy of each potential candidate is to accept the offer A or to reject the offer $\mathrm{R}$.

Presidential board. The presidential board wants to establish the order in which the potential candidates will be invited to maximize the expected number of points. In this way, the strategy for the presidential board will be the order in which the three potential candidates can be offered the vice-presidential nomination until at least one has accepted or all have rejected the offer P.

\section{Payoffs}

Presidential board. The presidential board payoff is the expected number of points of each possibility in the order of the proposal presented to the potential candidates.

Potential candidates. For these players it is possible to define: If the player accepts the offer, he/she gets the "total prize", that is, he/she gets payoff 1 . On the other hand, if he/she rejects the proposal, he/she does not get anything so his/her payoff will be 0 .

This game is an example of game theory application to human resources management (on this subject see also Andrade, Ferreira, \& Filipe, 2012; Ferreira et al., 2008; 2012; 2014; 2016; Ferreira, 1991; 2014; Filipe, Ferreira, \& Andrade, 2012; Matos \& Ferreira, 2005; Matos, Ferreira, \& Filipe, 2018).

\section{Code Form Representation for the Game}

To represent the game, code form game representation (see Ferreira \& Matos, 2018; Matos \& Ferreira, 2002a; 2002b; 2003; 2005) will be used. Code form is a table where the strategies that are available to any player, are codified. The table is built containing the whole game information. Table 2 is the code form representation for the game now considered. Reading from left to the right, the first column indicates the period number and the second column indicates the move ${ }^{2}$ number. The following columns mention who moves when and in what circumstances and what action is played when somebody is called upon to move. Last column indicates the payoffs vector in accordance with the strategies chosen by the players. It is easy to check that the order in which the three potential candidates can be offered the vice-presidential nomination must be (follow symbols in bold):

To invite in the first place the candidate classified in 2nd place, 2; if he/she rejects the proposal, the candidate classified in third place, 3 , should be invited and if he/she does not accept, the candidate classified in first place, 1 should be invited. The expected number of points is $7.6=7.2+0.4+0+0$.

\footnotetext{
${ }^{1}$ See Bicchieri et al., 1999.

2 See Benoit and Krishna, 1985 and Eberwein, 2000.
} 
Table 2

Code Form Game

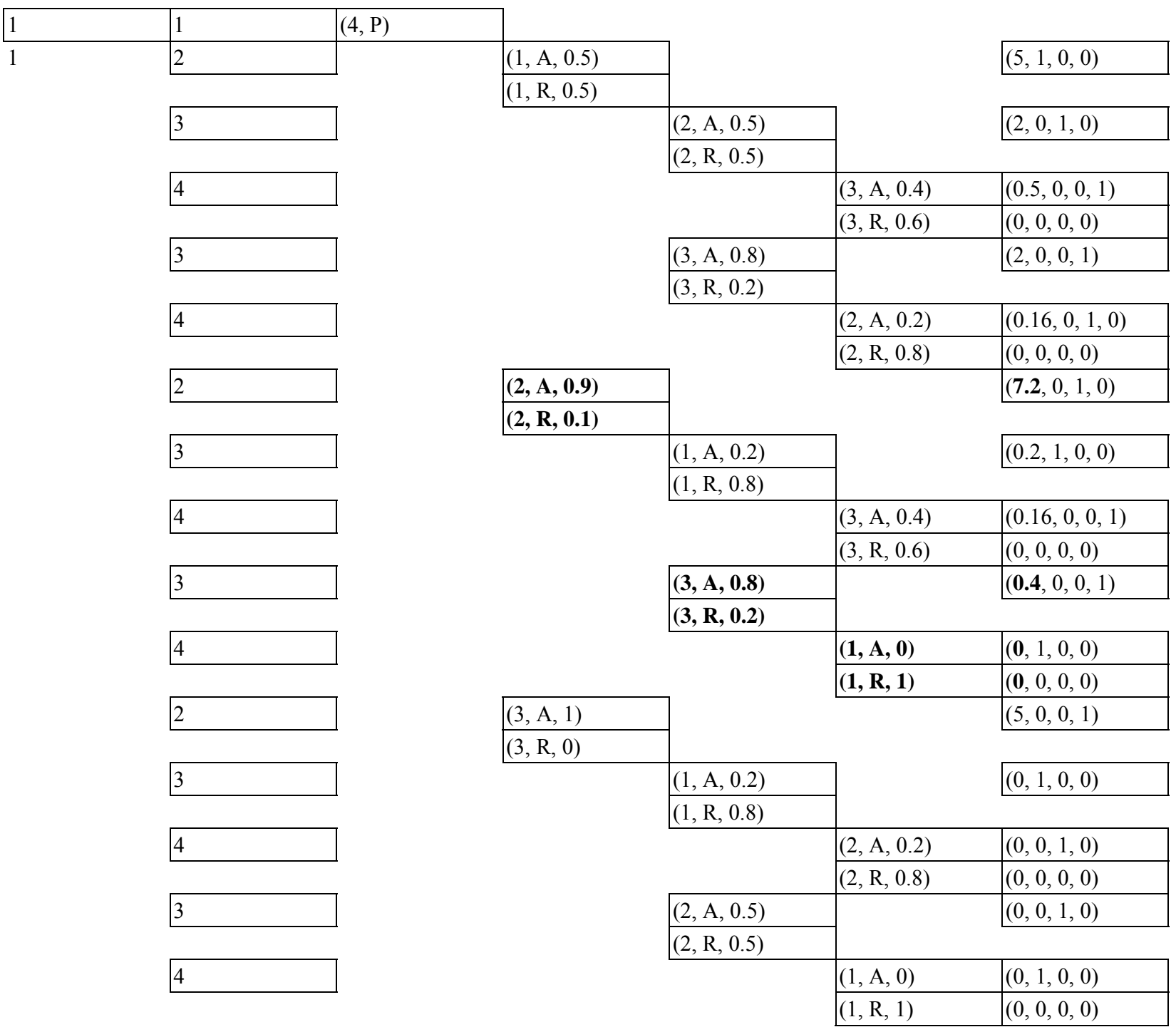

Note that the winning strategy (from the presidential board point of view) is weak in guarantying the existence of a vice-president in the end of the selection process. Indeed, if the first two candidates refuse the vice-presidency, it will be vacant since the best-classified candidate will certainly refuse when asked in third place.

This is an example of how, when it comes to modelling human behaviour, all criteria are debatable and have strengths and weaknesses. You have to be very careful in your choice, and the quantitative aspects are not necessarily the most important.

\section{Conclusions}

The analyzed game illustrates that the player who has decision power is not always the one who decides the game. In other words, the presidential board is the player who dominates the situation; therefore, they 
decide who the best candidate is. But, indeed, the ones who actually decide the game are the potential candidates when either they accept or they refuse the proposal. Really, the potential candidates are the ones who determine the game's outcome; starting from a situation of weakness they gain the control of the game. They are the result of the first part of the game and become the deciding elements of the second part of the game.

\section{References}

Andrade, M., Ferreira, M. A. M., \& Filipe, J. A. (2012). Representation of reserves through a Brownian motion model. SPMCS 2012, Book Series: Journal of Physics Conference Series, 394, Article Number: 012036. doi:10.1088/1742$6596 / 394 / 1 / 012036$

Bicchieri, C., Jeffrey, R., \& Skyrms, B. (1999). The logic of strategy. Oxford: Oxford University Press, Inc.

Benoit, J. P., \& Krishna, V. (1985). Finitely repeated games. Econometrica, 53, 890-904.

Eberwein, C. (2000). The sensitivity of repeated bargaining outcomes to the choice of first proposer. Ohio: Ohio State University

Ferreira, M. A. M. (1991). An infinite-server queuing system with an exponential busy period. In C. A. Braumann (Ed.), Proceedings of 15th Portuguese-Spanish Conference on Mathematics 1-6 (pp. D63-D66). Universidade de Évora, Évora, Portugal.

Ferreira, M. A. M. (2014). The pandemic period length modeled through queue systems. In Quantitative Methods in Economics (Multiple Criteria Decision Making XVII) (pp. 43-47). Virt, Slovakia: Vydavatel'stvo EKONÓM. Retrieved from http://fhi.sk/files/katedry/kove/ssov/proceedings/Zbornik2014.pdf [Accessed 2 February 2018]

Ferreira, M. A. M., Filipe, J. A., Coelho, M., \& Andrade, M. (2008). An infinite servers model for motor vehicles dismantling and recycling in a scarce energy ambience. In Quantitative Methods in Economics (Multiple Criteria Decision Making XIV) (pp. 178-186). High Tatras, Slovakia: IURA EDITION SPOL SRO. Retrieved from http://fhi.sk/files/katedry/kove/ssov/proceedings/Zbornik2008.pdf [Accessed 2 February 2018]

Ferreira, M. A. M., Andrade, M., \& Filipe, J. A. (2012). Studying pensions funds throug an infinite servers nodes network: A theoretical problem. SPMCS 2012, Book Series: Journal of Physics Conference Series, 394, Article Number: 012035. doi:10.1088/1742-6596/394/1/012035

Ferreira, M. A. M., Filipe, J. A., Coelho, M., \& Pedro, M. I. C. (2014). Chaos in world politics: A reflection: The "drop of honey effect”. In S. Banerjee, S. S. Ercetin, and A. Tekin (Eds.), Chaos theory in politics (pp.89-104). Book Series: Understanding Complex Systems, Springer Complexity. doi:10.1007/978-94-017-8691-1_6

Ferreira, M. A. M., Filipe, J. A., \& Coelho, M. (2016). Unemployment period quantitative approach through infinite servers queue systems. In Quantitative Methods in Economics (Multiple Criteria Decision Making XVIII) (pp. 89-94). Vrátna, Slovakia: Letra Interactive, s. r. o. Retrieved from http://fhi.sk/files/katedry/kove/ssov/proceedings/Zbornik2016.pdf [Accessed 2 February 2018]

Ferreira, M. A. M., \& Matos, M. C. P. (2018). A code form game in a selection process. In Quantitative Methods in Economics (Multiple Criteria Decision Making XIX) (pp. 96-103). Trenčianske Teplice, Slovakia: Letra Edu, s. r. o. Retrieved from http://www.fhi.sk/files/katedry/kove/ssov/proceedings/Zbornik2018.pdf [Accessed 5 June 2018]

Filipe, J. A., Ferreira, M. A. M., \& Andrade, M. (2012). Reserves represented by random walks. SPMCS 2012, Book Series: Journal of Physics Conference Series, 394, Article Number: 012034. doi:10.1088/1742-6596/394/1/012034

Gibbons, R. (1992). Game theory for applied economist. Princeton: Princeton University Press.

Kennan, J., \& Wilson, R. (1993). Bargaining with private informaiton. Journal of Economic Literature, 31(1), 45-104.

Matos, M. C. P., \& Ferreira, M. A. M. (2002a). Games in code form. Proceedings of the Fifth Spanish Meeting on Game Theory. Seville. July 1-3.

Matos, M. C. P., \& Ferreira, M. A. M. (2002b). Games in code form versus games in extensive form. In Quantitative Methods in Economics (Multiple Criteria Decision Making XI) (pp. 185-193). Nitra, Slovakia. Retrieved from http://fhi.sk/files/katedry/kove/ssov/proceedings/Zbornik2002.pdf [Accessed 2 February 2018]

Matos, M. C. P., \& Ferreira, M. A. M. (2003). Best payoff method. Proceedings of XV IMGTA. Italian Meeting on Game Theory and Applications. Urbino, Italy. 9-12 July, 2003.

Matos, M. C. P., \& Ferreira, M. A. M. (2005). Select and accept. In S. Blair, U. Chakraborty, S. H. Chen, et al. (Eds.), Proceedings of the 8th Joint Conference on Information Sciences, 1-3, 532-534. Salt Lake City, UT. July 21-26. 
Matos, M. C. P., Ferreira, M. A. M., \& Filipe, J. A. (2018). Let the games begin and Go on. Int. J. Business and Systems Research, 12(1), 43-52. doi:10.1504/IJBSR.2018.10009017

Selvarasu, A., Filipe, J. A., Ferreira, M. A. M., Agarwal, S. A., \& Pedro, M. I. C. (2009). A strategic profit model to measure Indian apparel retail performance. In M. Kovacova (Ed.), APLIMAT 2009: 8th International Conference, Proceedings (pp. 311-331). Bratislava, Slovakia.

Vega-Redondo, F. (2003). Economics and the theory of games. Cambridge: Cambridge University Press.

Weibull, J. (1995). Evolutionary game theory. Cambridge: MIT Press. 